\title{
The Effect of Demographic Variables and Ownership on Credit Card Market in Malaysia
}

\author{
Gholamreza Zandi ${ }^{1}$, Shaheen Mansori ${ }^{2}$ \& Ong Boon $\mathrm{Hai}^{3}$ \\ ${ }^{1}$ Universiti Kuala Lumpur Business School, Malaysia \\ ${ }^{2}$ Malaysian University of Science and Technology (MUST), Malaysia \\ ${ }^{3}$ Graduate School of Business, SEGi University, Malaysia \\ Correspondence: Shaheen Mansori, Malaysian University of Science and Technology (MUST), Malaysia.
}

Received: April 30, 2019

Accepted: May 30, 2019

Online Published: June 11, 2019

doi:10.5430/ijfr.v10n5p359

URL: https://doi.org/10.5430/ijfr.v10n5p359

\begin{abstract}
The aim of this research is to provide a framework for credit card providers to develop a better marketing strategy as well as business related to credit transaction by providing better understanding towards the effect of current individual demographic variable towards credit card ownership and usage in Malaysia. This research discusses the effect of significant demographic variables and ownership on the usage of credit card in Malaysia. The impacts of four key demographic variables are age, gender, education level, and income level on ownership and usage of credit card among credit cardholders in Malaysia. Whereas the income level has the strongest relationship among other demographic variables, it has to be taken into consideration by the credit card providers not just the ownership of credit card as well as the demographic variables while developing market strategy, particularly in Malaysia.
\end{abstract}

Keywords: individual bankruptcy, credit card usage, financial planning, personal debt

\section{Introduction}

The credit card had been commonly used in society and was part of our daily life in recent years. Many researches had been conducted regarding the topic of the user behaviour and ownership of credit card (Chien, Y. W., \& Devaney, S. A. 2001; Kaynak, E. and Harcar, T. (2001). Most of the research has concluded the findings on understanding on the different types of factors that have an impact on the ownership and usage of credit card for different individual groups in various countries, related to specific credit card providers in different countries (Vathsala, W. and Anurudh G. (2009); Halil, T. and Ferda, Y. T. (2010). As the situation and condition vary from country to country, in terms of micro-environment and macro-environment, studying the credit card ownership and usage in a specific country can help to provide a better understanding for a different country Philip, K. and Gary, A. (2006). Through better understanding these factors that have a significant impact on the ownership and usage of credit card, it can help credit card provider to develop and design better strategy to better facilitate credit card users as well as business that closely link with credit card usage in their daily business operation.

According to Hamilton, R., \& Mosahid Khan (2001), there are many variables such as laws and regulation, demographic variable of an individual, economic factor, consumers' behaviour and attitude as well as technology that has a significant impact or influence on the overall credit card ownership and usage in a particular country. Thus, this research aimed to find out the relationship of demographic variables of an individual with the ownership and usage of credit card in Malaysia Bird, E. J., Paul A. H., and Robert W. (2014); Durkin, T. A. (2000). The main demographic variables used in this research dissertation were age, gender, education level and income level of the individual to link with the ownership and usage of credit card in Malaysia.

Philip, K. and Gary, A. (2006) stated that the demographic environment has a major implication to most of the business, particularly for credit card related business. Thus, understanding the demographic profile of a different individual has to be taken into consideration of different credit card providers as the need of consumers or users of credit card vary from one another according to different demographic profile. Different authors and researchers also stated different opinions towards the effect and impact of individual demographic on the ownership and usage of the credit card with similar researches conducted. Lim et al. (2002) has conducted research in Malaysia and found out that there is a positive correlation of age with credit card ownership, indicating that there is a positive relationship 
between age and credit card ownership, by means higher the age, the higher the ownership of credit card in Malaysia. However, there were also researches conducted where there is a negative correlation between age and credit card ownership, such as in the United States of America (Wasberg et al. 1992; Wahba, 2016). Thus, it can be said that though individuals may share similar demographic variables their attitude and behaviour towards credit card may be different due to the micro-economics or macro-economic background that differ from country to country. This explains why the outcome of the research of Lim et al. (2002) and Wasberg et al. (1992) different from one another. Therefore, this research aimed to be carried out in order to find out the correlation between the demographic profile of an individual on credit card ownership and usage in Malaysia and therefore to provide an understanding and comparison where either the credit card users in Malaysia matching with the credit card users in other countries.

Hofstede, G. (1980) demonstrated that there are national and regional cultural groupings that affect the behaviour of individuals and organizations. According to Hofstede, G. (1980), there are different factors for explaining national cultures. Hence, though an individual may share similar demographic variable still may act differently depending on their culture and behaviour (Doyle, P. 2008; Obeid \& Awad 2018). As Malaysia is a very different country in terms of it was built up with multi-ethnic, therefore the results of findings may differ from other countries where consist of only one core ethnic group. Therefore, this research aims to examine the relationship between the demographic profile of an individual on credit card ownership and usage as overall as well as alongside with differentiating different ethnicity in Malaysia to compare the behaviour and outcome of different ethnicity (Obiekwe, 2018).

Apart of that, the researcher would also find out on the relationship between the ownership of credit card with the usage of credit card, which is similar to the findings of Lim et al. (2002) where their research found that the higher the credit cards ownership, it would lead to the higher credit cards usage in terms of frequency. Particularly where Bank Negara Malaysia (2016) has restricted the number of ownerships of credit card for individuals in recent years, it would be important to find out whether the credit card ownership would still have the same positive impact on the usage of credit card in Malaysia. According to

Halil, T. and Ferda, Y. T. (2010), if the relationship between these variables was positively correlated, it is important for credit card provider to develop new business strategy to increase their sales as in decrease in credit card ownership would directly link to decreasing of credit card usage and therefore would harm the overall profitability of credit card providers Busha, C. H. and Harter, S. P. (1980).

\section{Literature Review}

\subsection{History of Credit Card}

The first credit cards were issued by hotels in the United States of America early 20s Wells, R. O. N., \& García-Prada, O. (1980). However, credit cards only were introduced to Malaysia at mid-1970. Due to the risk attached to the credit card providers, finance charges were imposed on the outstanding balances (DeWitz, S. J., Woolsey, M. L., \& Walsh, W. B. 2009; Obinna-Echem \& Torporo 2018). At first, the credit card was only involved sales directly between the merchant who offer the credit and cardholders, but it started to accept each other's cards at 1938. In 1966, the general-purpose credit card was born, when the Bank of America established the Bank America Service Corporation that franchised the Bank America Card brand (also to be known as Visa currently) to banks nationwide. Another group of national credit card system was formed when a group of credit-issuing banks joined together and created the Inter Bank Card Association which is now known as Master Card Worldwide DeWitz, S. J., Woolsey, M. L., \& Walsh, W. B. (2009). Later on, credit card has been generalized and experienced significant growth throughout the globe as and slowly replacing cash and cash in a different kind of transaction. In current society, credit card no longer attached just for a high amount of luxury transaction but also almost applicable and available for daily life transaction (Lee, S. P. 2000; Obodo \& Anigbata 2018). In most of the modern developed countries, credit cards were introduced and viewed as an indication of a cashless society, with the aid of the advancement of technology. Throughout the period, though other forms of payment such as online services like PayPal and online banking were introduced but given a sheer volume of devices being used worldwide, credit cards are unlikely to pass from the scene any time soon (DeWitz, S. J., Woolsey, M. L., \& Walsh, W. B. (2009).

\subsection{Credit Card Trend Malaysia}

For recent years, regulators had imposed various rules and regulations in Malaysia. These rules as regulations were as followed (Bank Negara Malaysia 2016):

(i) The appliance must have at least RM 24,000 annual income to apply a credit card where previously only RM 18,000 annual income is required.

(ii) The cardholder who earns RM 36,000 or less only allowed holding a credit card from a maximum of two 
issuers where previously there is no restriction on holding credit card(s) from multiple credit card companies.

(iii) The maximum credit limit for credit card shall not exceed two times of their monthly income per issuer where the credit limit was set based on the credit card issuer's discretion previously.

As according to Bank Negara Malaysia (2016), such changes are to promote sound financial and debt management since credit card debts have been a growing concern of the society of Malaysia.

Table 1. Outstanding debts and bankruptcy rate arising from credit cards usage

\begin{tabular}{lllllll}
\hline Year & $\mathbf{2 0 0 9}$ & $\mathbf{2 0 1 0}$ & $\mathbf{2 0 1 1}$ & $\mathbf{2 0 1 2}$ & $\mathbf{2 0 1 3}$ & $\mathbf{2 0 1 4}$ \\
\hline Outstanding credit card debts (RM billion) & 28 & 31 & 33 & 35 & 37 & 41 \\
\hline $\begin{array}{l}\text { Individual who declare bankruptcy in Malaysia due } \\
\text { to credit card debts }\end{array}$ & 869 & 622 & 405 & 403 & 383 & 376 \\
\hline
\end{tabular}

Source: Bank Negara Malaysia (2016)

Referring to Table 1, there was a positive sign of individual who declared bankruptcy in Malaysia due to credit card debts. The number of the individual that declare bankruptcy starting from 2009 had decreased mainly due to the new credit cards regulations, Credit Card Act, 2009 (Caroline, C. 2009; Ok, et.al 2018). Alongside with the new rules and regulation, the numbers of those who declared bankruptcy had fallen between 2009 and 2014 (Yuta, S. 2011; Okon, 2018). These new rules and regulations by Credit Card Act, 2009 had brought a huge impact and changes towards credit card market in Malaysia as it increased the barrier for individuals to obtain a credit card, at the same time limiting the ownership of credit card in the market.

Malaysia mainly used E-money and credit cards as their payment instrument and lessor on charge card and debit card as the number of transaction and value were the highest for credit card and E-money. Hence, it can be said that credit card and E-money is much favoured in Malaysia than charge card and debit card. Comparing the value of the transaction, credit card has higher transaction value than e-money. With growing usage of the credit card as well as acceptance of credit card, it can be seen that consumers are demanding for credit Amir, A.B. (2011). Though there were restrictions of rules and regulations over the years, it doesn't have a significant impact on the growth of usage of credit card in the market (Yuta, S. 2011; Vafa, Sappington \& Coombs-Richardson 2018). According to Philip, K. and Gary, A. (2006) stated that micro-economic and macro-economic does affect an individual behaviour given that the group of people may share similar demographic variables. Hence, the researcher would like to review that whether the trend of credit card ownership or usage of the credit card were still the same as the micro-economic and macro-economic were changing over the year, such as with technological advancement as well as new rules and regulations came into effect. This research on studying the impact of demographic variables with ownership and usage of a credit card can provide a comparison of the relationship between these variables as the practice of behaviour may have changed over time (Okpechi, et. al., 2018).

\subsection{Consumer Attitude to Credit Card Ownership and Usage}

This section explains the reasons for owning a credit card as well as the behaviour of users of categorized. Chan, Y. K. (1996) in his study categorized the different types of card users into two different categories based on their usage frequency, which are "active cardholders" and "inactive cardholders". In his statement, "active cardholders" were those who use a credit card at least ten times per month while "inactive cardholders" were who use credit card less than ten times per month. On the other hand, Lee, J. and Hogarth, J.M. (1999) had categorized credit cardholders into two different categories, which are convenient user and revolving user. In their definition, the convenient user repays their outstanding balance in full on the monthly basis to avoid interest payment while revolving user used to have outstanding balances in their accounts, leading to them paying interest on outstanding balances. Besides that, Hamilton, R. and Mosahid Khan (2001) had categorized cardholders into three different categories which are non-active cardholders, active cardholders who not paying interest and active cardholders who paying interest. Similar to Chan, Y. K. (1996) definition, non-active cardholders were those who used credit card less than ten times per month. However, there is now a difference between active cardholders who not paying interest from active cardholders who paying interest are the cardholders will fully pay all their outstanding balances at the end of the month to avoid interest charges. Another study conducted by Ryan, G. (2011) had further categorized credit 
cardholders into five different categories:

- Max payers - cardholders who use their pay their outstanding balance in full within the interest-free period

- Revolvers - cardholders who use to carry debt which is the same as active cardholders who paid interest

- Deadbeats - Cardholders who never pay their credit card debts nor have the intention to repay

- Arbitragers - Cardholders who play with the system to make money from the $0 \%$ balance transfers

- Reformed credit card users (non- users) - cardholders who previously had problems with credit card debts and now they do not use or use their credit card(s) only when necessary or emergencies.

One of the surveys conducted by Malaysia local financial institutions, which are Malayan Banking, MBF Finance, and Hong Leong Bank revealed that banks in Malaysia categorized credit cardholders according to active and non-active users wherein usage rate of ten times per month was the cut-off point. Through understanding the different types of categories of card users, this would allow the researcher and readers to have a better understanding to study the behaviour of the credit card users, which would help to provide a more solid analysis for the result of this research dissertation that helps to contribute to credit card providers for developing better marketing strategy as well as customer relationship management (Olanrele, 2018).

\subsection{Different Types of Credit Card}

Currently, in Malaysia, there are different types of credit card available in the market. Overall, there are three different main categories of credit cards as shown in Table 2 which cater the diversified need of card users from different income groups. Classic card is the basic category of credit card which has the lowest credit limit where platinum is the highest categories of credit card which has the highest credit limit among all the credit card categories applicable in Malaysia. According to Fumiko, H. and Joanna, S. (2012), classic card normally for those who with low credit rating, thus with limitation of credit amount and has to maintain proper payment to improve their credit rating. One of the findings of Fumiko, H. and Joanna, S. (2012) also mentioned that cardholders with higher categories of card tend to spend more than the Classic card as they have more credit limit.

Table 2. Categories and key features of credit card

\begin{tabular}{ll}
\hline Categories & Features \\
\hline Classic Card & A basic card suitable for regular income or low credit rating holders. \\
\hline Gold Card & $\begin{array}{l}\text { An advance credit card for higher income levels or stronger credit rating holders. } \\
\text { It provides sufficient travel accident, inconvenience cover and wide range of } \\
\text { reward programs. }\end{array}$ \\
\hline Platinum Card & $\begin{array}{l}\text { It only offered by special invitation by the credit card issuers. It comes with } \\
\text { concierge services and exclusive offers with airlines, premier hotels, and } \\
\text { restaurants. }\end{array}$
\end{tabular}

Source: Economy Watch (2016)

Another research conducted by Lim et al. (2002) also found that is a significant relationship between the category of credit card owned by the cardholder and credit card usage level. The results showed that $60 \%$ of the active cardholders were gold cardholder while $80 \%$ of the inactive customers were Classic cardholder in Malaysia. Thus, this shows that the categories of the cardholder have a significant impact on the usage of the card.

Apart from categories of cards, there are also different types of credits card available, each with different features shown in Table 3.

Table 3. Types and key features of credit card

\begin{tabular}{ll}
\hline Types & Features \\
\hline Co-branded credit cards & $\begin{array}{l}\text { Offered by credit card issuers in partnership with various retail brands } \\
\text { and service providers. They come with special discounts and offers on } \\
\text { products of the partnering brand. }\end{array}$ \\
\hline
\end{tabular}


Reward credit cards

Offer "reward" in the form of cash backs, points or shopping rewards on purchases and payments.

Low APR and Balance Come with 0\% or low APR (or low APR) and low rates on balance

Transfer credit cards transfer.

Business credit cards

These cards generally come with the option of supplementary cards for employees, to cater to their business travel expenses. It personalized with the company name and these cards provide access to an extensive network of seminars and business events.

$\begin{array}{ll}\text { Islamic credit cards } & \text { Card transactions are administered on the basis of Islamic banking } \\ \text { principles and these cards come with the option of direct zakat payment } \\ \text { facility. }\end{array}$

Student credit cards

Normally provided for high school or college students with the low credit limit and less incentive

Source: Economy Watch (2016)

\subsection{Credit Card Ownership and Credit Card Usage}

The findings of Lim et al. (2002) found that the number of ownerships of credit card has a positive relationship with the usage of the credit card. The findings found that $86.5 \%$ of the inactive cardholders hold three or lesser cards whereas $56.8 \%$ of active cardholders hold more than three cards. This phenomenon was said to improve as higher credit limit, as well as more card features, were given to the cardholders in Malaysia. Apart of that, another study by Tuğay, O., \& BAŞGÜL, Ö. G. N. (2007) shown that $60 \%$ out of all the respondents who use credit cards in their expenditures think that credit cards ownership made them spend more than they need as credit cards enable them to enjoy the features to buy now but to pay it later. Therefore, cardholders tend not to feel like spending as they used the credit card for later payment instrument. The findings also show that individuals who hold several cards tend to have higher credit card usage. This was also supported by another study by Halil, T. and Ferda, Y. T. (2010) where they found that there is a positive relationship between credit card ownership and usage in Turkey.

\subsection{Demographic Variables}

This section explains on the demographic variables that were wide explained in the previous section, particularly on four key demographic variables, which are age, gender, education level and income level in relation to the ownership and usage of the credit card.

\subsubsection{Relationship Between Demographic With Ownership of Credit Card}

This sub-section will review the four key demographic variables in relation to ownership of credit card in different countries.

\subsubsection{Age}

The study by Wasberg et al. (1992) stated that there is a negative relationship between age and credit card ownership in the United States. This means that the older an individual, the lesser the credit cards they own. One of the arguments was that as the credit card was fairly new during the 90 s, younger people tend to have better acceptance towards new technology which in this case inclined with the acceptance towards credit card than older people. Trust on the credit card system was whereby stopping the older generation to accept a credit card as a financial mechanism for payment. Thus, the older generations' ownership is lower than the younger generation Chien, Y. W., \& Devaney, S. A. (2001). However, the research outcome was, later on, be challenged by the work of other researchers where they found that there was a positive relationship between age and ownership Vathsala, W. and Anurudh G. (2009). This can be explained as these researches were conducted later on whereby people have more acceptance towards credit card compared with during in the 90 s whereas the later researches were conducted in the 20th century. Kaynak, E. and Harcar, T. (200) and findings found that age does affect the ownership of credit card in Turkey positively which means that the older generation tends to own more credit cards. Their research was then further supported by Lim et al. (2002) and Vathsala, W. and Anurudh G. (2009) as results showed that there is a positive relationship between age and ownership of credit card in Malaysia and Sri Lanka. Lim et al. (2002) stated that credit cards were a symbol of privilege and status for an individual in Malaysia. As one grew older, they tend to have a higher status in society with a well-developed career, thus therefore applicable for more ownership of credit card. There was also a 
sign that older generations used to own more credit cards to show their privilege over the younger generations. Another point highlighted by Vathsala, W. and Anurudh G. (2009) was whereby older generation tends to have more expenditure than the younger generation, such as house commitment and more household expenses, therefore, more ownership of credit card would help to leverage their expenses, as compared with the younger generation. The review of the literature shows most of the research and findings that there was a positive relationship between age and ownership of credit card. Various studies have highlighted the factor of why age does have an influence over ownership of credit cards, such as more expenditure and better financial status than the younger generation.

\subsubsection{Gender}

Regarding gender, Adcock et al. (1997) stated that males are more likely to own more credit cards than females. This was explained whereby male was the sole income earner in the family, controlling household finance and subsequently will own more credit card than female. A study carried out in Malaysia by Lim et al. (2002) shown also that males tend to own credit card more than females because females used to have weaker financial capabilities a as compared with males in Malaysia. In order to avoid the risk of getting into debt, females tend to avoid credit card ownership. However, these results were challenged by Vathsala, W. and Anurudh G. (2009) as their findings showed that females tend to have more ownership of credit card than male. This was related to the factor that female favour towards the rewards and benefits offered by credit card providers and male seem less attracted to these rewards and benefits compared to female, thus leading to female having more credit card ownership than male. Based on the literature review, Adcock et al. (1997) may not reflect on the current situation as the research was conducted during the 90s. However, the later findings of Lim et al. (2002) and Vathsala, W. and Anurudh G. (2009) both came out with different results. Thus, the researcher would like to evaluate whether which result is more applicable for the current situation in Malaysia through examining the relationship between gender and ownership of the credit card.

\subsubsection{Education Level}

Durkin, T. A. (2000) stated that that lack of understanding has a high probability to bring the cardholders into over-indebtedness situation. Therefore, education level may play an important factor in the ownership of a credit card. As higher education level means the individual has a better understanding of credit card charges, this means that people with higher education level will tend to have more ownership as they understand and know how to obtain the benefits of credit card, as compared with individual with lower education level (Berlin, M. and Mester, L. J. (2004); Kim, T., Dunn, L.F. and Mumy, G.E. 2005). Research by Kaynak, E. and Harcar, T. (2001) also found that there is a positive relationship between ownership of credit card and education level. This is because an individual with a higher education level tends to be more willing to try or accept new things as compared with those with a lower education level. Their research was proven where $90 \%$ of their participants who own more than three credits card were with at least academic qualification of a bachelor's degree. This was supported by research conducted by Vathsala, W. and Anurudh G. (2009) in Sri Lanka, where the results showed that individual with higher education level tends to own credit card more than those who have lower education level. This was mainly due to the individual with a higher education level has the knowledge and understanding to interpret the benefits that could be obtained from credit card ownership. Another research by Lee, J. and Kwon, K. (2002) stated that $60 \%$ of the individual who owns more than one credit card has a degree or higher level of education among all the respondents in Singapore. Based on the literature review, various results and findings proven that there was a positive relationship between education level and ownership of credit card. This also indicated that such a relationship has a lesser effect by different culture background or countries. The research also would like to examine the relationship between education level and ownership of credit card in Malaysia whether the relationship is positive as proven by other researchers.

\subsubsection{Income Level}

One of the findings of Vathsala, W. and Anurudh G. (2009) shown that in Sri Lanka found that individual with lower income level feel that credit card encourage them to spend beyond their income and tempt them to spend on something that they do not needs which cause them to fall into debt circumstances. However, the individual with higher income level tends to have more ownership of credit card as they believed that credit card could help to improve their quality of life and lifestyle. On the other hand, Halil, T. and Ferda, Y. T. (2010) findings shown that that individual with higher income level tends to own more credit cards than those who have lower income in Turkey. This is because an individual with lower income level tend to be much more cautious on spending and consequently leading to lesser number of card subscription while higher income individual tends to have more confidence in repayment of debts which may encourage them to have more credit card ownership. 


\subsubsection{Relationship Between Demographic With Usage of Credit Card}

This sub-section will review the four key demographic variables in relation to the usage of credit card in different countries.

\subsubsection{Age}

Barker, A.T. and Sekerkaya, A. (1992) had investigated on the globalization credit card usage in Turkey and the outcome of the research shown that age group of 25-45 years old tend to use credit cards more than the others age groups. This is mainly because for the age group they tend to spend beyond their earnings, thus they may use a credit card to leverage their spending. According to Halil, T. and Ferda, Y. T. (2010), credit card usage still with a negative correlation with age in 2010. One of the main reasons was the older generation were reluctant to accept credit card and have no intention to replace cash with a credit card. The author also explained that the culture of 'spend now, pay later' among the younger generation was one of the main reasons for higher credit card usage for the younger generation than the older generation. However, Lim et al. (2002) later found out that in Asian countries, there is a positive correlation between age and usage of a credit card. They concluded that there was a significant relationship between age and credit card usage level as $80 \%$ of the respondents were at least 30 years old when it comes to high usage of a credit card. Lee, J. and Kwon, K. (2002) also found that there was a positive relationship between age and credit card usage because Singapore is a well-developed country and the older generation has no issues with using a credit card. The findings of Barker, A.T. and Sekerkaya, A. (1992) and Halil, T. and Ferda, Y. T. (2010) shown that there is a negative correlation between age and credit card usage while other studies which proved that there is a positive correlation between these variables (Lim et al., 2002; Lee, J. and Kwon, K. 2002). As these researches were conducted in the different region around the globe, the researcher would like to examine the relationship between age and usage of credit card and to compare with similar researches conducted in Asia and to test whether the relationship between such variables still remains the same in the current situation.

\subsubsection{Gender}

Hayhoe, C. R., Leach, L. J., Turner, P. R., Bruin, M. J., \& Lawrence, F. C. (2000) stated that gender has a relationship with the usage of a credit card. Similar to the study conducted by Cavus, M. F. (2006), it stated that among the credit cards users who used more than 5 times, male consist of $65 \%$ of that particular group. The main driver was male tend to have more acceptance towards risk and new technology and female and leading to more willing to use more credit card than female. This was further supported by the findings of Schuh, S. D., \& Stavins, J. (2011) in the United States of America where results showed that $81 \%$ of the male tends to use credit cards as payment instruments where only $75 \%$ of the female use credit cards as payment instruments. However, Kucukemiroglu and Ozmen (1995) stated that the credit card usage in Turkey is not affected by the gender which means there is no relationship between genders towards credit card usage where male and female tends to be equally same on credit card usage. This was also supported by Joo et al. (2001) where there is no difference between genders when it comes to credit card usage as the outcome of the research findings shown that male and female were equally same on credit card usage, regardless of active or non-active. As various results and findings were with a different outcome, where some stated that male tend to have more credit card usage than female while the rest stated that there is no relationship when it comes to gender and usage of a credit card.

\subsubsection{Education Level}

Kucukemiroglu and Ozmen (1995) stated that the education level of an individual is positively related to credit card usage. This means that the higher the education level, the higher the usage of the credit card of an individual. This was also supported by the findings of Halil, T. and Ferda, Y. T. (2010) in Turkey there is a positive relationship between education level and credit card usage. An individual with a higher education level tends to use a credit card more frequent as compared to an individual with a lower education level. The results are supported by various researchers and authors (Choi and Devaney 1995; Schuh, S. D., \& Stavins, J. 2011; Wang \& Yang 2018). Choi and Devaney (1995) highlighted that the education level has an effect on the credit card usage in the United States of America because an individual with higher education level has the knowledge and ability to get benefits that might not be seen by those with lower education level. Therefore, individuals with higher education level tend to use a credit card more often as they know how to obtain benefits than those with lower education level. This statement of positive relationship and correlation between education level and usage of credit card also supported by Schuh, S. D., \& Stavins, J. (2011) where their research findings show that there was only $82 \%$ among individual with lower education level use credit cards as payment instrument where there was $95 \%$ among with bachelor degree or above or individual with higher education level use credit cards as their payment instruments. 


\subsubsection{Income Level}

Lastly, Lim et al. (2002) stated that there is a significant relationship between income level and credit card usage level in Malaysia. This was proven with their results that $83 \%$ of the active credit cardholders in Malaysia earn more than RM 4, 000 per month. This means that active credit cardholder is those with higher income level and individual with lower income level tend to have lower usage of a credit card. Lee, J. and Kwon, K. (2002) also supported the findings above where results show that individual with higher income tends to use the card more than those who have lower income. This is mainly due to an individual with lower income tend to be worried to build up debt unintentionally and therefore avoid using a a card. Higher income individual also tends to be less worried on the repayment of debt and therefore willing to use a credit card more than lower income group.

On the other hand, Cavus, M. F. (2006) found out that individual with lower income tends to use more credit card than a higher income group. This is mainly because of the instalment instrument available in the market. Therefore, the lower income group tend to use a credit card more for purchase via instalment whereas this wasn't attracting the higher income group. Ritzer (2008) also supported the statement whereby lower income group tend to use more credit cards to leverage their expenditure and therefore will have more usage than higher income group.

\subsection{Conceptual Framework}

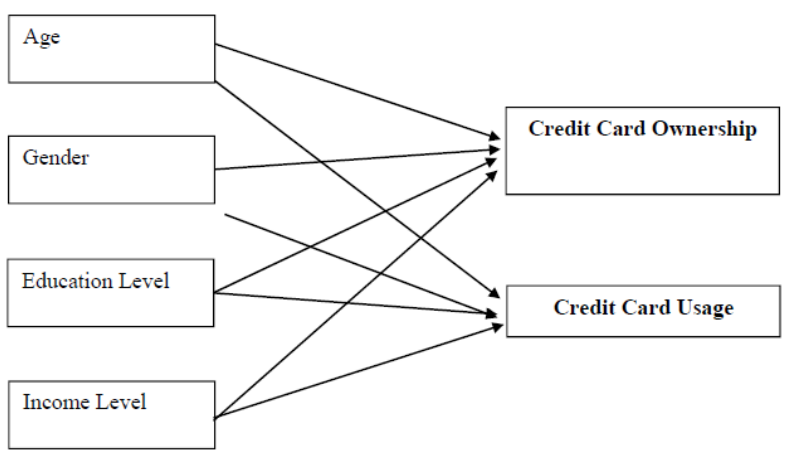

Based on the above review, studies that focus on the impact of demographic factors on the ownership and amount of usage of credit card have shown high inconsistency in results and it is advisable that in future more researches consider to further explore these relationships. Thus, the following propositions have been developed in order to test and examine and test the relationship:

- Proposition 1: There is a correlation between age and ownership of a credit card.

- Proposition 2: There is a correlation between age and the amount of usage of a credit card.

- Proposition 3: There is a correlation between gender and ownership of a credit card.

- Proposition 4: There is a correlation between gender and the amount of usage of a credit card.

- Proposition 5: There is a correlation between education level and ownership of a credit card.

- Proposition 6: There is a correlation between education level and the amount of usage of a credit card.

- Proposition 7: There is a correlation between income level and ownership of a credit card.

- Proposition 8: There is a correlation between income level and the amount of usage of a credit card.

- Proposition 9: There is a correlation between ownership of a credit card and the amount of usage of a credit card.

\section{Discussion and Conclusion}

Fill, C. (2006) stated that understanding consumers' needs could help firms develop a better marketing strategy. The main aim of this study is to provide a framework for credit card providers to develop a better marketing strategy as well as business related to credit card ownership and usage. Though several studies have been conducted on the relationship between the demographic profile of an individual and the impact on the ownership and usage of a credit card (Lim et al. 2002; Halil, T. and Ferda, Y. T. 2010), the review of the literature has shown that there is a high 
level of inconsistency in results and views of different authors and researchers. As Bird et al. (2014) rightly stated, consumer attitude changes from time to time and it can be due to various factors such as economic, technology and/or socio-cultural changes.

\section{References}

Adcock, W. O., Hirschman, E. C., \& Goldstucker, J. C. (1997). Bank credit card users: an updated profile. Advances in Consumer Research, 4, 336-341.

Amir, A. B. (2011). Payment Systems in Malaysia: Recent Developments and Issues. Retrieved 3 August 2016, from http://www.adbi.org/working-paper/2011/09/16/3328.paymen t.systems.malaysia/

Bank Negara Malaysia. (2016). Bank Negara Malaysia. Retrieved 18 August 2016, from http://www.bnm.gov.my/index.php?ch=ps\&pg=ps_stats\&eId=box 1

Barker, A. T., \& Sekerkaya, A. (1992). Globalization of credit card usage: the case of a developing economy. International Journal of Bank Marketing, 10, 27-31. https://doi.org/10.1108/02652329210017299

Berlin, M., \& Mester, L. J. (2004). Credit card rates and consumer search. Review of Financial Economics, 13, 79-198.

Bird, E. J., Paul A. H., \& Robert, W. (2014). Credit Cards and the Poor Institute for Research on Poverty. Discussion Paper, No. 1167-9. Madison, W1: University of Wisconsin.

Busha, C. H., \& Harter, S. P. (1980). Research Methods in Librarianship Techniques and Interpretation, p. 63. New York: Academic Press.

Caroline, C. (2009). Consumer Guide: How the Credit CARD Act of 2009 Affects You. Retrieved 24 July 2016, from http://www.credit.com/credit_information/credit_law/Credit-CARD-Act-of-2009.jsp

Cavus, M. F. (2006, September). Personal finance in obtaining credit cards: Credit card in Turkey a research on use. School of Social Sciences Journal, 15, 173-189.

Chan, Y. K. (1996). Demographic and Attitudinal Differences Between Active and Inactive Credit Cardholders-The Case of Hong Kong. International Journal of Bank Marketing, 15(4), 117-125. https://doi.org/10.1108/02652329710189375

Chien, Y. W., \& Devaney, S. A. (2001). The effects of credit attitude and socioeconomic factors on credit card and installment debt. Journal of Consumer Affairs, $35(1), \quad$ 162-179. https://doi.org/10.1111/j.1745-6606.2001.tb00107.x

Choi, H. N., \& DeVaney, S. (1995). Factors Associated with the Use of Bank and Retail Credit Cards. In S. B. Mackenzie \& D. M. Stayman (Eds.), Proceedings of the Society for Consumer Psychology. LaJolla, CA: American Psychological Association.

DeWitz, S. J., Woolsey, M. L., \& Walsh, W. B. (2009). College student retention: An exploration of the relationship between self-efficacy beliefs and purpose in life among college students. Journal of College Student Development, 50(1), 19-34. https://doi.org/10.1353/csd.0.0049

Doyle, P. (2008). Marketing Management and Strategy. Pearson Education Limited, 2, 100-120.

Durkin, T. A. (2000). Credit cards: Use and consumer attitudes, 1970-2000. Fed. Res. Bull., 86, 623.

Economy Watch. (2016). Malaysia Credit Cards. Retrieved 24 July 2016, from http://www.economyw-atch.com/malaysia-credit-cards/

Fill, C. (2006). Marketing Communication. Pearson Education, 4, 216.

Fumiko, H., \& Joanna, S. (2012). Effects of Credit Scores on Consumer Payment choice. Consumer Payments Research Center.

Halil, T., \& Ferda, Y. T. (2010). Factors affecting credit card uses: Evidence from Turkey using Tobit Model. European Journal of Economics, Finance and Administrative Science, 23, 87-101.

Hamilton, R., \& Khan, M. (2001). Revolving Credit Card Holders: Who are they and How Can They Be Identified?. The Services Industries Journal, 21(3), 37-48. https://doi.org/10.1080/714005031

Hayhoe, C. R., Leach, L. J., Turner, P. R., Bruin, M. J., \& Lawrence, F. C. (2000). Differences in spending habits and credit use of college students. Journal of Consumer Affairs, 34(1), 113-133. https://doi.org/10.1111/j.1745-6606.2000.tb00087.x 
Hofstede, G. (1980). Culture's Consequences: International Differences in Work-Related Values. Beverly Hills, California: Sage Publications.

Joo, S., Grable, J., \& Bagwell, D. (2001). College students and credit cards. Proceedings of the Association for Financial Counselling and Planning Education, 8-15.

Kaynak, E., \& Harcar, T. (2001). Consumers' attitudes and intentions towards credit card usage in an advanced developing country. Journal of Financial Services Marketing, 6, 24-39. https://doi.org/10.1057/palgrave.fsm.4770038

Kim, T., Dunn, L. F., \& Mumy, G. E. (2005). Bank competition and consume research over credit card interest rates. Economic Inquiry, 43, 344-353. https://doi.org/10.1093/ei/cbi023

Lee, J., \& Hogarth, J. M. (1999). Returns to information search: consumer credit card shopping decision. Financial Counselling and Planning, 10, 23-34. https://doi.org/10.1111/j.1745-6606.2000.tb00097.x

Lee, J., \& Kwon, K. (2002). Consumers' use of credit cards: store credit card usage as an alternative payment and financing medium. The Journal of Consumer Affairs, 36, 239-262. https://doi.org/10.1111/j.1745-6606.2002.tb00432.x

Lee, S. P. (2000). Credit Card Considerations. The Star.

Lim, H. C. T., Ramayah, N. N., \& Aizzat, M. N. (2002). Cardholders' attitude and bank credit card usage in Malaysia: An exploratory study. Asian Academy of Management Journal, 7, 122-134.

Obeid, R., \& Awad, B. (2018). Interaction of Monetary and Macro-prudential Policies: The Case of Jordan-Credit Gap as an Example. Asian Journal of Economics and Empirical Research, 5(1), 99-111. https://doi.org/10.20448/journal.501.2018.51.99.111

Obiekwe, O. (2018). Human Capital Development and Organizational Survival: A Theoretical Review. International Journal of Management and Sustainability, 7(4), 194-203. https://doi.org/10.18488/journal.11.2018.74.194.203

Obinna-Echem, P. C., \& Torporo, C. N. (2018). Physico-Chemical and Sensory Quality of Tigernut (Cyperus Esculentus)-Coconut (Cocos Nucifera) Milk Drink. Agriculture and Food Sciences Research, 5(1), 23-29. https://doi.org/10.20448/journal.512.2018.51.23.29

Obodo, N. A., \& Anigbata, D. O. (2018). Challenges of Implementing Electronic Governance in Public Sector Organizations in Nigeria. International Journal of Applied Economics, Finance and Accounting, 2(1), 30-35. https://doi.org/10.33094/8.2017.2018.21.30.35

Ok, S., Suy, R., Chhay, L., \& Choun, C. (2018). Customer Satisfaction and Service Quality in the Marketing Practice: Study on Literature Review. Asian Themes in Social Sciences Research, 1(1), 21-27. https://doi.org/10.33094/journal.139.2018.11.21.27

Okon, P. E. (2018). Comparative Analysis of Mass Media Coverage of the Fight Against Corruption in Nigeria by the Obasanjo and Buhari Administrations. International Journal of Emerging Trends in Social Sciences, 4(2), 47-57. https://doi.org/10.20448/2001.42.47.57

Okpechi, P. A., Denwigwe, C. P., Asuquo, P. N., Abuo, C., \& Unimna, F. U. (2018). Awareness and Utilization of e-Learning Resources by Trainee Counsellors of Counselling Education in Calabar, Nigeria. International Journal of Educational Technology and Learning, 3(2), 45-51. https://doi.org/10.20448/2003.32.45.51

Olanrele, I. (2018). Revisiting Electricity-Economic Growth Nexus in Sub-Sahara Africa: Perspectives from Nigeria and South Africa. International Journal of Management and Sustainability, 7(3), 180-193. https://doi.org/10.18488/journal.11.2018.73.180.193

Philip, K., \& Gary, A. (2006). Principles of Marketing. Pearson Education Ltd, 11, 69-75.

Ryan, G. (2011) 5 Types of Credit Card Users- Credit Card Company Perspective. Retrieved 4 September 2016, from http://cashmoneylife.com/5-types-of-credit-card-users/

Schuh, S. D., \& Stavins, J. (2011). How consumers pay adoption and use of payments. https://doi.org/10.2139/ssrn.2564179

Tuğay, O., \& Başgül, Ö. G. N. (2007). Önemli Bir Finansman Kaynaği Olarak Kredi Kartlari: Kredi Kartlarinin Kart Sahiplerinin Harcamalari Üzerindeki Etkisini Belirlemeye Yönelik Burdur İlinde Bir Araştirma. Süleyman Demirel Üniversitesi Iktisadi ve İdari Bilimler Fakültesi Dergisi, 12(3), 215-226. 
Vafa, S., Sappington, K., \& Coombs-Richardson, R. (2018). Using Augmented Reality to Increase Interaction in Online Courses. International Journal of Educational Technology and Learning, 3(2), 65-68. https://doi.org/10.20448/2003.32.65.68

Vathsala, W., \& Anurudh, G. (2009, July). Consumer Credit Card Ownership and Usage practices: Empirical Evidence from Sri Lanka. International Journal of Consumer Studies, 33(4), 436-447. https://doi.org/10.1111/j.1470-6431.2009.00779.x

Wahba, M. (2016). Emotional Workgroup Performance and Group Effectiveness Egyptian Context. International Journal of Business, Economics and Management, 3(10), 122-132. https://doi.org/10.18488/journal.62/2016.3.10/62.10.122.132

Wang, K., \& Yang, Z. (2018). The Research on Teaching of Mathematical Understanding in China. American Journal of Education and Learning, 3(2), 93-99. https://doi.org/10.20448/804.3.2.93.99

Wasberg, C. A., Hira, T. K., \& Fanslow, A. M. (1992). Credit card usage and consumer debt burden of households. Journal of Consumer Studies and Home Economics, 16, 19-32. https://doi.org/10.1111/j.1470-6431.1992.tb00496.x

Wells, R. O. N., \& García-Prada, O. (1980). Differential analysis on complex manifolds (Vol. 21980). New York: Springer. https://doi.org/10.1007/978-1-4757-3946-6

Worthington, A. C. (2006). Debt as a Source of Financial Stress in Australian Households. International Journal of Consumer Studies, 30, 2-15. https://doi.org/10.1111/j.1470-6431.2005.00420.x

Worthington, S. (1990). Retailer Credit Cards: A Competitive Threat. International Journal of Bank Marketing, 8(4). https://doi.org/10.1108/02652329010001784

Yuta, S. (2011). The Advantages and Disadvantages of Credit Card in the U.S. 